\title{
GARANTÍAS DE PROTECCIÓN DEL DERECHO FUNDAMENTAL AL AGUA EN MÉXICO: UN PANORAMA
}

\section{GUARANTEES OF PROTECTION OF THE FUNDAMENTAL RIGHT TO WATER IN MEXICO: A PANORAMA}

\section{Rodrigo GUTIÉRREZ RIVAS}

RESUMEN: El artículo está centrado en las garantías de protección del derecho fundamental al agua en México. Parte de la teoría multinivel de las garantías de los derechos considerando una primera subdivisión clave entre garantías institucionales y garantías sociales. En seguida quedan expuestas las vías utilizables por personas y comunidades para defender su derecho de acceso al agua, con miras a obtener una cantidad mínima indispensable y satisfacer las necesidades diarias de consumo personal y doméstico. El artículo expone la complejidad de la defensa de este derecho y abre el debate sobre la necesaria participación de los actores afectados.

Palabras clave: derechos humanos, derecho al agua. garantías institucionales, garantías sociales, protección jurisdiccional, teoría multinivel.
ABSTRACT: This article focuses on the guarantees of protection of the fundamental right to water in Mexico. It starts up in the multilevel of the fundamental rights guarantees considering a first key subdivision between the institutional guarantees and the social guarantees. Immediately are exposed ways that can be used by persons and communities to defend their right of access to water, with the purpose of obtaining a minimum and indispensable quantity and to satisfy the daily needs of personal and domestic consumption. The article exposes the complexity of the defense of this right and opens a debate around the necessary participation of the affected actors.

Descriptors: Human Right to Water, Institutional Guarantees, Social Guarantees, Jurisdictional Protection, Multilevel Theory. 


\section{INTRODUCCIÓN}

En su 29o. periodo de sesiones, el Comité de Derechos Económicos Sociales y Culturales ${ }^{1}$ de las Naciones Unidas (Comité DESC) discutió la Observación General 15 (OG 15), derivada de los artículos $11.1^{2}$ y $12^{3}$ del Pacto Internacional de Derechos Económicos Sociales y Culturales (PIDESC). ${ }^{4}$ La OG 15 fue aprobada dos meses después, ${ }^{5}$ convirtiéndose así en el documento internacional más relevante sobre el derecho fundamental al agua. En él se precisa el contenido de este derecho y las obligaciones que adquieren los Estados firmantes del Pacto en la materia. ${ }^{6}$

Aunque no es el objetivo de este trabajo profundizar en el contenido del derecho y las obligaciones que adquiere el Estado frente a éste, conviene recordar que de acuerdo con la OG 15 del PIDESC, "El derecho humano al agua es el derecho de todos a disponer de agua suficiente, salubre, aceptable, accesible y asequible para uso personal y doméstico".

En sintonía con este esfuerzo internacional de construcción jurídica, una multiplicidad de movimientos y organizaciones a nivel mundial han emprendido diversas acciones para exigir el reconocimiento constitucional del derecho al agua. México no ha sido la excepción; en marzo de 2006 se constituyó la Coalición de Organizaciones Mexicanas por el Derecho al Agua (COMDA) que desde esa fecha ha encabezado una campaña nacional que lucha por el reconocimiento explícito de ese derecho en la Constitución. En los dos últimos años, ese esfuerzo ha sido reforzado por diversas propuestas de reforma constitucional impulsadas desde las cámaras de representantes. Se trata, sin duda, de estrategias muy relevantes que no deben cesar y que es necesario seguir impulsando.

Sin embargo, la importancia y gravedad del tema no permite que sigamos haciendo una única apuesta en la lucha por el derecho al agua y los

1 Celebrado en Ginebra del 11 al 29 de noviembre de 2002.

2 Derecho a un nivel de vida adecuado.

3 Derecho a la salud.

4 Ratificado por México el 18 de diciembre de 1980. Decreto publicado en el Diario Oficial de la Federación del 12 de mayo de 1981. La vinculación de México es desde el 23 de marzo de 1981.

5 E/C.12/2002/11 20 de enero de 2003.

6 Aunque la OG 15 es el documento más preciso sobre la materia, el derecho al agua ha sido reconocido en un importante número de instrumentos internacionales. Los más relevantes pueden consultarse en: Gutiérrez, Rodrigo et al., El agua y el desarrollo rural, México, CEDRSSA, 2007, pp. 166 y ss. 
recursos hídricos. Los problemas de sobrexplotación, ${ }^{7}$ contaminación, discriminación ${ }^{8}$ y privatización están provocando que millones de niños y niñas mueran por beber agua contaminada; ${ }^{9}$ que millones de mujeres y niñas sigan estando obligadas a dedicar varias horas de su vida diaria para acarrear agua hasta sus casas; ${ }^{10}$ que centenas de comunidades indígenas y campesinas sufran el despojo o la sobrexplotación de sus acuíferos y manantiales o la discriminación en el acceso a una cantidad de agua

7 En México, las tasas de extracción en alrededor de la cuarta parte de sus acuíferos son $20 \%$ más rápidas de lo que tardan en recargarse, lo que provoca una peligrosa disminución de los niveles freáticos y en consecuencia una sobrexplotación de los mantos. Informe sobre desarrollo humano 2006, Programa de las Naciones Unidas para el Desarrollo (PNUD), p. 141.

8 Cuatro de cada diez viviendas indígenas, en nuestro país, no tiene agua entubada. Existen más de siete mil localidades indígenas que no tienen agua en los domicilios, lo que afecta a un millón de personas. En otras tres mil localidades, el 75\% de las viviendas no tienen agua, lo que afecta a cerca de dos millones de personas más. Como ejemplo extremo de la discriminación que sufren los indígenas, las comunidades purépechas en el país tienen un consumo de 12 litros por habitante al día, lo que las coloca en uno de los patrones de consumo más bajos del mundo. Véase Gálvez, Xóchitl, Los pueblos indígenas de México y el agua, 2006, ponencia presentada en el IV Foro Mundial del Agua.

9 En México este asunto reviste enorme importancia y gravedad debido a que las enfermedades gastrointestinales son la segunda causa de mortalidad infantil (278 de cada 100 mil). Véase Castellan, Enrique, "La situación del recurso hídrico en México", en Barkin, David, Innovaciones mexicanas en el manejo del agua, México, UAM-CTMMAIWRA, 2001.

10 Sorprende de manera negativa que las instituciones gubernamentales especializadas de nuestro país no hayan construido datos sobre cuántas mujeres y cuánto tiempo dedican al acarreo de agua para el uso doméstico. Existe una cifra del Instituto Nacional de Geografía y Estadística (INEGI) según la cual las mujeres utilizan 58.90 horas para el acarreo de agua; sin embargo, la información no especifica de qué sector femenino se trata y cuál es su tamaño, de qué región del país, y el lector debe inferir que son horas por semana; véase Instituto Nacional de las Mujeres, La encuesta de uso del tiempo y sus potencialidades para conocer las inequidades de género, México, Inmujeres, 2003, p. 65. Al respecto el Fondo de Desarrollo de las Naciones Unidas para la Mujer (UNIFEM) señala que a nivel mundial "las mujeres y los niños, preferentemente niñas, utilizan más de 8 horas diarias recorriendo 10 a $15 \mathrm{kms}$. trasladando entre 20 y 15 litros de agua por viaje" [en Mujer, medio ambiente, agua: reflexiones sobre la promoción y protección del derecho de las mujeres al agua, UNIFEM, consultado en http://www.cinu.org.mx/even tos/agua/presUNIFEM.doc] 
suficiente, aceptable y económicamente accesible para su uso personal y doméstico. $^{11}$

Además, porque si bien es cierto que en el texto actual de nuestra norma suprema no existe un artículo en el que podamos encontrar un fraseo como: todas las personas tiene el derecho al agua, sí podemos encontrar en ella elementos que nos permiten decir que ese derecho se encuentra implícitamente reconocido en la norma suprema. En primer lugar, porque el derecho al agua guarda una relación de interdependencia ${ }^{12}$ con otros derechos reconocidos en la Constitución mexicana, como pueden ser la salud o la vivienda (artículo 4o.) que son de imposible ejercicio si las personas no tienen acceso a una cantidad mínima de agua potable. ${ }^{13}$ En segundo lugar porque en diversos artículos de la Constitución (2o., 4o. y 27) se establecen obligaciones hacia los poderes públicos que están relacionadas con el contenido mínimo esencial de ese derecho (cuando menos en los casos de pueblos indígenas y de niños y niñas). ${ }^{14}$ Además por-

11 Los estados de Oaxaca, Chiapas y Guerrero muestran los niveles de disponibilidad de agua más elevados de México gracias a las grandes precipitaciones que tienen lugar en dichas zonas; sin embargo, también poseen las tasas más bajas de acceso a agua potable. PNUD, op cit., nota 7, p. 55.

12 Esta relación de dependencia que existe entre los derechos ha sido reconocida jurídicamente en el derecho internacional a través de la noción de interdependencia que se encuentra establecida en el punto 13 de la Declaración de Teherán (1968) y reiterada en el punto 5 de la Declaración de Derechos Humanos de Viena (1993).

13 Así ha sido reconocido en el derecho internacional a través de las observaciones generales aprobadas por el Comité DESC. De acuerdo con la Observación General 4 (Vivienda adecuada) para determinar si una vivienda cumple con el concepto de adecuación, es necesario que ésta cuente con "ciertos servicios indispensables para la salud, la seguridad, la comodidad y la nutrición. Todos los beneficiarios del derecho a una vivienda adecuada deberían tener acceso permanente a recursos naturales y comunes, a agua potable...". En relación con el derecho a la salud, la Observación General 14 en su párrafo 4 establece que la referencia que se hace en el artículo 12 del PIDESC "al más alto nivel posible de salud física y mental no se limita al derecho a la atención de la salud. Por el contrario, el historial de la elaboración y la redacción expresa del párrafo 2 del artículo 12 reconoce que el derecho a la salud abarca una amplia gama de factores socioeconómicos que promueven las condiciones merced a las cuales las personas pueden llevar una vida sana, y hace ese derecho extensivo a los factores determinantes básicos de la salud, como la alimentación y la nutrición, la vivienda, el acceso a agua limpia potable y a condiciones sanitarias adecuadas...".

14 Lo anterior no debería ser impedimento para que los ciudadanos puedan exigirlo y las autoridades, protegerlo y cumplirlo. De hecho, en situación muy similar se encuentra el derecho a la vida, el cual sin estar reconocido de forma expresa en ningún artículo 
que dicho derecho ha sido reconocido en múltiples instrumentos internacionales firmados y ratificados por México.

Por las razones anteriores, se hace necesario - y posible - comenzar a emprender acciones jurídicas y políticas, en múltiples escalas, para exigir que ese derecho se respete, proteja y cumpla. Aunque ello ha comenzado a intentarse - tanto desde el ámbito de la sociedad civil ${ }^{15}$ como de las instituciones - ${ }^{16}$ es necesario multiplicar los esfuerzos, identificando y accionando todas aquellas posibles vías de protección del derecho al agua. Debido a que desde el ámbito de la teoría ya se han elaborado un número importante de documentos que precisan el contenido del derecho y las obligaciones que se desprenden de éste, ${ }^{17}$ ahora es necesario profundizar en las estrategias concretas y posibles mecanismos de defensa del derecho al agua. En esa dirección apunta este trabajo, cuyo objetivo principal es identificar y clasificar las distintas garantías que hoy pueden ser ya ejercitadas en nuestro país para luchar por el acceso a un bien sin el cual la vida y la dignidad de las personas es imposible.

Antes de iniciar, conviene advertir que dicho ejercicio de clasificación se basa en una concepción compleja del concepto de garantías. ${ }^{18}$ Esto último nos conducirá a hacer referencia no sólo a las vías de justiciabilidad del derecho sino también a otras estrategias de exigibilidad que involucran acciones, tanto de los propias personas y comunidades afectadas, como de una multiplicidad de órganos e instituciones que pueden y están obligados a intervenir en la protección de los recursos hídricos: órganos

constitucional, ha sido configurado a través de la interpretación de la Suprema Corte, señalando que está implícitamente reconocido.

15 En abril de 2008 se reunió en el Instituto de Investigaciones Jurídicas de la UNAM un grupo de abogados y científicos de distintas disciplinas (juristas, biólogos, hidrólogos y economistas) que analizaron la situación de cuatro comunidades afectadas y junto con organizaciones de la sociedad civil discutieron importantes líneas estratégicas de defensa del derecho al agua.

16 Recomendación de la Comisión de Derechos Humanos del Distrito Federal.

17 Gutiérrez Rivas, Rodrigo, "El derecho fundamental al agua en México: un instrumento de protección para las personas y los ecosistemas", Cuestiones Constitucionales, núm. 18, México, enero-junio de 2008. Langford, M. y Ashfad, K., "Introducción al agua como derecho humano", en Fundación Heinrich Böll, La gota de la vida: hacia una gestión sustentable y democrática del agua, México, 2006.

18 Véase Pisarello, Gerardo, Los derechos sociales y sus garantías; elementos para una reconstrucción, Madrid, Trotta, 2007. 
legislativos, administrativos y otras instituciones de vigilancia y control previstas en el ordenamiento jurídico mexicano.

\section{EL CONCEPTO GENERAL DE GARANTÍA}

Debido a la confusión que existe en nuestro país entre las nociones de garantía y derecho, ${ }^{19}$ es conveniente iniciar aclarando lo que en este trabajo habrá de entenderse cada vez que aparezca el concepto garantía.

Para ello, conviene referirse a un creciente consenso de la doctrina según el cual las garantías deben ser entendidas como los mecanismos o técnicas de tutela, diseñadas para proteger y asegurar la efectividad de los derechos. ${ }^{20}$ En sentido amplio, este concepto se refiere a los instrumentos que permiten al titular del derecho (individual o colectivo) acceder al bien que integra su contenido. Se trata de aquellos mecanismos que tienen el objetivo de asegurar que los poderes cumplan con las obligaciones que se desprenden de los derechos. Como lo ha señalado Ferrajoli, las garantías son herramientas basadas en una suerte de desconfianza frente a la promesa de respeto espontáneo y satisfacción de los derechos por parte de quienes ejercen el poder. ${ }^{21}$

\section{GARANTÍAS EN MÉXICO}

Para comprender el alcance y los límites de las garantías del derecho al agua dentro del sistema jurídico mexicano, conviene partir de un conjunto de categorías teóricas — con sus correspondientes subdivisiones-

19 Debido, entre otras razones, al hecho de que al capítulo I, del título primero de la Constitución de 1917, se le denominó "De las garantías individuales", en nuestra tradición jurídica se ha utilizado la noción de garantía como sinónimo de derecho fundamental. Ello dificulta la comprensión de muchos de los debates contemporáneos que hoy están teniendo lugar en el ámbito del constitucionalismo de los derechos.

20 Como ejemplos de dichas posiciones teóricas y que serán las que orientan las reflexiones de este trabajo, véase Ferrajoli, Luigi, "Garantías", Jueces para la Democracia, Madrid, núm. 38, julio de 2000, pp. 39-46. Pisarello, Gerardo, "El Estado social como Estado constitucional: mejores garantías, más democracia", en Abramovich, Víctor y Courtis, Christian (comps.), Derechos sociales; instrucciones de uso, México, Fontamara, 2003. Abramovich, Víctor y Courtis, Christian, Los derechos sociales en el debate democrático, Madrid, Bomarzo, 2006, p. 55.

21 Ferrajoli, Luigi, "Garantías", op. cit., nota anterior, p. 39. 
que son necesarias para profundizar en la materia. La primera gran subdivisión que es útil establecer - basada en los sujetos a los que se encarga la protección del derecho- es la de 1) garantías institucionales y 2) garantías sociales. 22

1) Las garantías institucionales son los mecanismos de protección encomendados a los poderes públicos. Para comprender las formas de interacción compleja que éstas tienen dentro de los sistemas jurídicos, conviene a su vez subdividirlas basándose en dos criterios: a) el de los órganos políticos a los que se encomiendan las garantías, y b) el del alcance de los propios mecanismos de garantía.

Atendiendo al primer criterio (órganos) puede distinguirse entre garantías políticas (encargadas a diversos órganos políticos y de control) y garantías jurisdiccionales (encargadas al Poder Judicial). Basándonos en el segundo criterio (alcance de los mecanismos) podemos hablar de garantías primarias y garantías secundarias. ${ }^{23}$ Las primarias son aquellas a través de las cuales se especifica el contenido de los derechos así como las obligaciones que se desprenden de los mismos. Las secundarias están diseñadas como vía para la reparación de la inobservancia de las primarias; operan en caso de que los poderes incumplan con las obligaciones establecidas por las garantías primarias.

En términos generales podría decirse que las garantías políticas son las mismas que las primarias, y que las garantías jurisdiccionales tienen una correspondencia directa con las secundarias; sin embargo, cuando se profundice en la clasificación de todas ellas, veremos que existen garantías políticas (encargadas a poderes políticos) que son secundarias (operan cuando las autoridades incumplen). Las posibilidades de defensa del agua que estas últimas nos ofrecen, es lo que nos obliga a realizar esta categorización compleja.

2) Las garantías sociales, también denominadas extrainstitucionales, son aquellas en las que la vigilancia y la protección del derecho es protagonizada por los propios sujetos titulares del derecho y afectados en sus intereses. Como lo ha subrayado Ferrajoli, es sobre estas últimas donde

22 Seguimos aquí los lineamientos (con algunos ajustes al sistema jurídico mexicano) de Luigi Ferrajoli, Víctor Abramovich, Christian Courtis y Gerardo Pisarello.

23 Ferrajoli, Luigi, "Garantías", op. cit., nota 20, pp. 40 y ss. 
"descansa la efectividad de las garantías internas o jurídicas y, con ellas, del Estado de derecho y de la democracia." 24

Todos estos tipos de garantías encuentran formas de ejercicio en una multiplicidad de niveles y escalas (internacional, regional, federal, estatal y municipal) que habrán de ser explicados y ejemplificados en los párrafos siguientes para construir un panorama general del gran árbol de garantías que existe en México para defender el derecho fundamental al agua.

\section{GARANTÍAS INSTITUCIONALES}

Siguiendo lo anterior, podemos decir que los mecanismos institucionales de garantía del derecho al agua en México tienen dos variantes: las garantías políticas y las garantías jurisdiccionales.

\section{Garantías políticas}

\section{A. Primarias}

Como ya se adelantó, se trata de los mecanismos de resguardo que están a cargo de los poderes políticos ${ }^{25}$ y tienen como objetivo principal determinar el contenido del derecho, los sujetos que quedan obligados por éste y el alcance de las obligaciones que se desprenden del mismo. Concretamente son ese conjunto de normas y actos que los poderes legislativos (incluyendo al Constituyente, o poder de reforma) o ejecutivos (federales, estatales o municipales) adoptan para tutelar el derecho. Van desde el reconocimiento constitucional del derecho, hasta los programas y políticas municipales referentes al agua, pasando por la legislación ordinaria o los reglamentos de las autoridades administrativas federales y estatales. Todos ellos dan concreción al derecho estableciendo los medios y recursos para hacerlo efectivo.

Por su privilegiada posición y su capacidad de influencia sobre todo el sistema jurídico, las garantías políticas más relevantes son las garantías

24 Ferrajoli, Luigi, Derecho y razón, 4a. ed., Madrid, Trotta, 2000, p. 942.

25 Al reflexionar sobre este tipo de garantías quedamos obligados a abandonar las concepciones liberales ortodoxas sobre el Estado - que en el terreno de los derechos lo conciben sólo como una potencial amenaza de las libertades - para concebirlo como una entidad instrumental con la obligación y capacidad de proteger y asegurar los derechos. 
constitucionales. Esto es, los instrumentos o mecanismos de tutela establecidos en la propia Constitución.

Una primera garantía constitucional, genérica, ${ }^{26}$ de carácter formal, es la rigidez constitucional. Tener una Constitución rígida como eje principal del ordenamiento jurídico — como ocurre en el caso mexicano-,${ }^{27}$ supone contar con una gran esfera de protección que impide a las mayorías políticas, o al mercado, afectar el núcleo esencial de los derechos que sean incluidos en ella. Se trata de una esfera de lo no decidible para la política y de lo no accesible para el mercado. Por lo tanto, al elevar a rango constitucional el derecho al agua, se asegura que el bien protegido por el derecho ${ }^{28}$ no quede a merced de los intereses de las mayorías políticas o de las presiones privatizadoras. Que en la Constitución mexicana podamos encontrar en diversos artículos un reconocimiento implícito de este derecho es ya una forma de protección del mismo. Evidentemente se robustecería la garantía constitucional si se incluyera una redacción explícita del derecho al agua en alguno de los artículos tal y como se ha hecho en muchas otras Constituciones del mundo. ${ }^{29}$

Como segunda garantía, conviene referirse al diseño institucional de la mayoría de las Constituciones contemporáneas basado en el principio de separación de poderes. Esta estructura institucional se convierte en una garantía instrumental de los derechos. El hecho de que exista una división de funciones entre los poderes del Estado, a través de la cual se configure un sistema de controles y contrapesos entre las autoridades estatales, introduce en el orden jurídico un conjunto de mecanismos que permite la vigilancia mutua entre centros de decisión para el cumplimiento de sus obligaciones en materia de derecho al agua.

En México, las facultades de control y vigilancia que tiene el Poder Legislativo sobre el Ejecutivo pueden ser eficaces como garantías de

26 Relativa a todos los derechos.

27 La rigidez supone un procedimiento dificultado de reforma constitucional. En el caso mexicano es el artículo 135 el que establece dicho procedimiento.

28 El derecho de todos a disponer de agua suficiente, salubre, aceptable, accesible y asequible para el uso personal y doméstico. OG 15 del Comité DESC.

29 Son varios los países donde ya se ha elevado a rango constitucional el derecho al agua. En las Constituciones de Uganda, Sudáfrica, Ecuador y Uruguay se reconoce el derecho de forma explícita. En las de Cambodia, Colombia, Eritrea, Etiopía, Guyana, Gambia, Irán, Laos, Nigeria, Panamá, Portugal, Venezuela y Zambia hay un reconocimiento explícito de obligaciones para el Estado. Véase Legal Resources for the Right to Water: International and National Standards, Ginebra, Sources 8, 2004, pp. 46-52. 
control en la materia; por ejemplo, los poderes legislativos pueden exigir la comparecencia del titular de la Secretaría del Medio Ambiente y los Recursos Naturales o del director general de la Comisión Nacional del Agua (CNA) para que informen sobre su desempeño en el respeto, protección y cumplimiento del derecho. Asimismo, el Legislativo podría constituir una comisión especial para investigar las actividades, los ejercicios presupuestales y el cumplimiento de programas y políticas por parte de las entidades de la administración pública. Lo que aquí interesa subrayar es que existen un número importante de mecanismos ordinarios de presión y vigilancia que pueden ser aprovechados por los poderes legislativos para investigar el uso de los recursos públicos o el sentido y la conveniencia de las políticas públicas puestas en marcha en la materia.

En casos más graves de corrupción, desvío de fondos o violación grave del derecho al agua, se podría incluso acudir a mecanismos de control extraordinarios como es el juicio político previsto en los artículos $109 \mathrm{y}$ 110 de la Constitución. Si de la violación del derecho al agua se pudieran desprender responsabilidades delictivas, también se podría ejercer la declaración de procedencia prevista en el artículo 111 de dicha norma suprema.

Dos garantías más son: 1) el principio representativo sobre el que están construidos los sistemas constitucionales contemporáneos, y 2) la publicidad de los actos de gobierno. De la primera derivan facultades a cargo de los legisladores, como puede ser la iniciativa legislativa o de reforma constitucional, que son también una forma de proteger el derecho. Recientemente en México han sido utilizadas ambas en multiplicidad de ocasiones para modificar la Constitución o la Ley de Aguas Nacionales; si alguna de estas iniciativas se esforzara en armonizar la legislación local con los tratados internacionales, priorizando el derecho fundamental al agua — que por cierto es una obligación internacional que asumió el gobierno mexicano al firmar el PIDESC_- estas vías se convierten en una garantía de ese derecho. En segundo lugar, el hecho de que la actividad de la administración deba ser pública y transparente, también se traduce en una garantía de control político que puede ser aprovechada por alguna otra autoridad estatal o incluso por la propia ciudadanía para controlar la administración y correcta gestión del agua.

Ahora bien, junto a estas garantías constitucionales de carácter genérico, también podemos encontrar garantías políticas específicas relaciona- 
das con las condiciones que la norma suprema impone a los poderes para que éstos doten de contenido mínimo a los derechos, designen a los titulares que puedan ejercerlos, establezcan las vías para el ejercicio, identifiquen a las autoridades responsables en la protección del mismo y precisen los deberes y obligaciones a los que dichas autoridades quedan vinculados. ${ }^{30}$

Como ya lo hemos dicho en párrafos anteriores, en la Constitución mexicana existen mandatos constitucionales dispersos en diversos artículos (2o., 4o. y 27), que establecen algunos elementos del contenido mínimo del derecho, obligan a diversas autoridades a emprender acciones para asegurar la disponibilidad y el acceso al agua, e identifican a determinadas personas y colectivos como titulares del derecho. ${ }^{31}$

Por ejemplo, en relación con los pueblos indígenas, el artículo 2o. de la Constitución Política de los Estados Unidos Mexicanos establece en su apartado A fracción V que los indígenas, en el ejercicio de su autonomía, tendrán el derecho a "Conservar y mejorar el hábitat y preservar la integridad de sus tierras..."; asimismo, en la fracción VI se establece el derecho de estos colectivos de "acceder... al uso y disfrute preferente de los recursos naturales de los lugares que habitan...", lo que evidentemente incluye ríos, manantiales y otras fuentes de agua con las que se abastecen dichas comunidades.

En el apartado B fracción IV de ese mismo artículo se establecen como obligaciones para las tres esferas de gobierno (federal, estatal y municipal) las de "Mejorar las condiciones de las comunidades indígenas y de sus espacios para la convivencia y recreación, mediante acciones que faciliten el acceso al financiamiento público y privado para la construcción y mejoramiento de vivienda, así como ampliar la cobertura de los servicios sociales básicos", lo que obviamente incluye el acceso al agua.

Por su parte, el artículo 27 constitucional (que regula la propiedad de las aguas nacionales) en su fracción VII, obliga al legislador a proteger la integridad de las tierras indígenas para el asentamiento humano, y regular "el aprovechamiento de tierras, bosques y aguas de uso común y la

30 Abramovich, Víctor y Courtis, Christian, Los derechos sociales en el debate... cit., nota 20, p. 58 .

31 De acuerdo con la Observación General 15, tanto disponibilidad como acceso son dos factores que conforman el contenido esencial del derecho fundamental al agua. 
provisión de acciones de fomento necesarias para elevar el nivel de vida de sus pobladores". Este apartado, junto con los señalados anteriormente, están vinculados al contenido esencial del derecho al agua en sus factores de disponibilidad y acceso para pueblos indígenas.

Por lo que tiene que ver con los niños, el artículo 4o. constitucional, en su párrafo 6 establece que "los niños y las niñas tienen derecho a la satisfacción de sus necesidades de alimentación, salud, educación y sano esparcimiento para su desarrollo integral". Aunque no se alude de forma expresa al agua, es obvio que esta forma parte de la alimentación adecuada y que sin ella la salud infantil es impensable.

En términos de obligaciones, el párrafo 7 de ese mismo artículo establece que los ascendientes, tutores y custodios tienen el deber de preservar estos derechos y que "el Estado proveerá lo necesario para propiciar el respeto a la dignidad de la niñez y el ejercicio pleno de sus derechos". ${ }^{32}$ Este es un claro mandato a todas las autoridades estatales para que provean todo lo necesario en el aseguramiento del ejercicio pleno de los derechos de niños y niñas; es evidente que si el Estado no asegura el acceso al agua potable a este sector de la población, todos los demás derechos de este grupo de personas se ponen en riesgo. ${ }^{33}$

Como puede observarse, en los artículos anteriores es posible encontrar algunos elementos que tanto el legislador como otros poderes públicos, deben respetar cuando ejerzan sus facultades regulatorias en materia de agua. Sin embargo, se trata de mandatos dispersos que no han sido desarrollados integralmente y por tanto no acaban de perfilar con precisión el contenido mínimo del derecho al agua en nuestra Constitución.

32 El artículo 24 punto 2 inciso c de la Convención sobre los Derechos del Niño establece que los Estados parte asegurarán la plena aplicación del derecho a un nivel de vida adecuado y en particular adoptarán las medidas apropiadas para "Combatir las enfermedades y la malnutrición en el marco de la atención primaria de la salud mediante, entre otras cosas, la aplicación de la tecnología disponible y el suministro de alimentos nutritivos adecuados y agua potable, teniendo en cuenta los peligros y riesgos de contaminación del medio ambiente".

33 En este sentido, la Observación General 15 establece que "el agua es un recurso natural limitado y un bien público fundamental para la vida y la salud". Por ello, el derecho humano al agua es indispensable para vivir dignamente y es condición previa para la realización de otros derechos humanos. Un abastecimiento adecuado de agua salubre es necesario para evitar la muerte por deshidratación y reducir el riesgo de las enfermedades relacionadas con el agua. 
Sin embargo, existen otras fuentes del derecho a las cuales las autoridades están obligadas a acudir para avanzar en la construcción del contenido esencial mínimo del derecho al agua. Nos referimos a los pactos y tratados internacionales en materia de derecho humanos, así como a los criterios, recomendaciones y observaciones que han ido construyendo los órganos especializados de Naciones Unidas (ONU) o de la Organización de Estados Americanos (OEA) en sus labores de vigilancia e interpretación de los compromisos internacionales. En nuestro país, a partir de una sentencia de amparo dictada por el pleno de la Suprema Corte de Justicia en 1999 en la que realizó una interpretación del artículo 133 constitucional, estas fuentes de derecho tiene un estatus privilegiado, aun cuando se encuentren por debajo de la Constitución pero por encima de todas las leyes, reglamentos y cualquier otra norma secundaria. ${ }^{34}$ En el caso del derecho al agua, resulta especialmente importante el trabajo realizado por los relatores especiales de la ONU y las diversas observaciones generales aprobadas por el Comité DESC que han abordado la materia, especialmente la OG 15 que ha profundizado en la construcción de este derecho.

A esta labor de concreción y clarificación del contenido mínimo del derecho deberían sumarse los ministros y ministras de la Corte. Ellos, a través de la facultad de interpretación constitucional, deberían aportar elementos argumentativos que permitan desarrollar el contenido esencial del derecho al agua, así como lo han hecho con otros derechos. Desgraciadamente, las viejas tesis doctrinales y jurisprudenciales que siguen considerando a los derechos sociales como cláusulas programáticas continúan pesando en contra de la construcción de un Estado constitucional de derecho y a favor de un sistema jurídico que deja amplios espacios de discrecionalidad a la administración para que ésta instrumente políticas públicas como meras prestaciones que suelen ser otorgadas bajo criterios asistenciales, clientelares o electorales y que en última instancia, por no ser consideradas derechos en estricto sentido, pueden ser revocadas.

Junto a la garantía de contenido mínimo, nos interesa destacar dos mecanismos más útiles para el control del contenido del derecho al agua que

34 Así lo estableció el Pleno de la Suprema Corte de Justicia a partir de una interpretación que realizó del artículo 133 constitucional en la tesis 192,867, cuyo título es "TRATAdOS INTERNACIONALES. SE UBICAN JERÁRQUICAMENTE POR ENCIMA DE LAS LEYES FEDERALES Y EN UN SEGUNDO PLANO RESPECTO DE LA CONSTITUCIÓN FEDERAL", véase Semanario Judicial de la Federación y su Gaceta, t. X, noviembre de 1999, novena época, pleno, tesis p. LXXVII/99, p. 46. 
permiten disciplinar el ejercicio de facultades de los poderes cuando emprendan labores de desarrollo y reglamentación del mismo. Se trata de la garantía de no regresividad y la de no discriminación establecidas en el PIDESC. La primera deriva del artículo 2.1 del Pacto, ${ }^{35}$ que establece como obligación de los Estados parte el desarrollo progresivo de los derechos (principio de progresividad). Como contraparte de dicha obligación surge una prohibición de regresividad que impide a los poderes impulsar leyes o reglamentaciones que supongan un retroceso en el goce del derecho. ${ }^{36}$ Se trata de una garantía de estabilidad de lo ya conquistado en materia de derecho al agua y cualquier medida que debilite al derecho tiene una presunción de ilicitud o inconstitucionalidad.

Por su parte, la prohibición de discriminación impide a los poderes públicos establecer en las leyes, en los reglamentos o a través de políticas públicas distinciones de trato no justificadas basadas en motivos de color de piel, género, lengua, edad, origen social o nacional, religión, opinión política, posición económica o cualquier otra condición social. Por lo tanto, excluir a un grupo de personas que posean los rasgos arriba indicados de la posibilidad de acceder a una cantidad mínima indispensable de agua de calidad para su uso personal, supone una fuerte presunción de discriminación. En México está garantía queda reforzada a partir de la incorporación constitucional del derecho a no ser discriminado que en agosto de 2001 se consagró en el párrafo 3 del artículo 1o. constitucional.

Ahora bien, debe recordarse que a partir de la incorporación del principio de igualdad material dentro del constitucionalismo moderno, el Estado puede establecer distinciones de trato, justificadas y constitucionales cuando su objetivo sea compensar a los sectores de la población que se encuentren en situación de mayor debilidad (favor debilis). No se puede olvidar que el derecho al agua, como parte del conjunto más amplio de los derechos sociales, es una vía a través de la cual se busca equi-

35 En dicho artículo se establece que "cada uno de los Estados partes en el presente Pacto se comprometen a adoptar medidas, tanto por separado como mediante la asistencia y la cooperación internacionales, especialmente económicas y técnicas hasta el máximo de los recursos que se disponga, para lograr progresivamente, por todos los medios apropiados, inclusive en particular la adopción de medidas legislativas, la plena efectividad de los derechos aquí reconocidos".

36 Un análisis teórico de fondo sobre esta garantía puede encontrarse en Courtis, Christian (comp.), Ni un paso atrás; la prohibición de regresividad en materia de derechos sociales, Buenos Aires, Del Puerto, 2006. 
parar a las personas y grupos que en una sociedad han sido colocadas en situación de marginalidad. El derecho al agua es un instrumento jurídico, que acompañado de todos los demás derechos busca asegurar la vida digna de las personas, pero especialmente de aquellas que por razones de discriminación han sido colocados dentro del sistema económico y político en posición de marginación, explotación o sometimiento cultural. Por lo tanto, instrumentos de compensación como las acciones afirmativas deben también contemplarse como posibles garantías de acceso al agua de determinados grupos históricamente excluidos de dicho acceso.

\section{B. Secundarias}

Como lo destacamos en los párrafos introductorios a este apartado, existen un conjunto de garantías que, encomendadas a órganos políticos, tienen el objetivo de controlar y reparar la violación de una garantía primaria.

Un primer ejemplo de ellas, cuyo papel en la protección del derecho al agua puede tener gran relevancia, es el poder de policía que suele ser encomendado a la administración. Éste resulta especialmente útil para establecer controles preventivos y de sanción sobre los poderes privados que puedan vulnerar el derecho al agua. Si tomamos en cuenta que el mayor potencial de contaminación o sobrexplotación de las aguas en el país lo tiene la industria, resulta de enorme relevancia contar con instrumentos de vigilancia que supervisen el cumplimiento de disposiciones legales o reglamentarias vinculadas con el derecho. Es el caso de la Comisión Nacional del Agua (CNA) quien tiene la facultad de vigilar que se cumplan las normas oficiales (NOMs) en materia de disponibilidad del agua o de calidad de la misma.

En 1996 y 1997 la CNA y el Instituto Nacional de Ecología emitieron tres NOMs - que sintetizan 44 anteriores - que regulan la contaminación del agua que proviene de todas las ramas industriales y del drenaje urbano y municipal. La NOM-001-ECOL-1996 que establece los límites máximos permisibles de contaminantes en las descargas de aguas residuales en aguas y bienes nacionales; su vigilancia corresponde a la CNA y a la Secretaría de Marina. La NOM-002-ECOL-1996 que también establece límites permisibles pero de las descargas en sistemas de alcantarillado y cuya vigilancia corresponde a los gobiernos estatales, municipa- 
les y del Distrito Federal. La NOM-003-ECOL-1996 que establece los límites de contaminantes para aguas residuales tratadas que se usen para el servicio público en cuya vigilancia también participa la Secretaría de Salud. ${ }^{37}$

Por su parte, la CNA ha emitido otras 12 NOMs, algunas de las cuales están estrechamente vinculadas con el contenido del derecho al agua en alguno de sus elementos, sobre todo con los de accesibilidad, disponibilidad y calidad. En el tema de disponibilidad es especialmente importante la NOM-011-CNA-2000, donde se establecen las especificaciones y el método para determinar la disponibilidad media anual de las aguas nacionales. En lugares donde hay sobrexplotación de los mantos acuíferos, agotamiento de pozos y manantiales esta norma es de especial importancia ya que de su contenido depende que se pueda seguir o no extrayendo agua.

La dependencia encargada de la vigilancia de estas últimas NOMs es la Secretaría de Medio Ambiente a través de la CNA y su incumplimiento debe ser sancionado conforma a lo dispuesto por la Ley de Aguas Nacionales y su reglamento.

También es conveniente referirnos al conjunto de recursos administrativos que existen al interior de las dependencias de la administración pública y que le permiten a los ciudadanos solicitar a la administración que revise alguna decisión que se considere equivocada. Estas vías, que existen en las dependencias encargadas de la vigilancia y administración del agua, son también garantías encargadas a órganos políticos pero que están diseñadas con el objetivo de reparar el incumplimiento de las garantías primarias.

Desgraciadamente el grado de cumplimiento de todas estas normas, y la capacidad de control y vigilancia por parte de las instituciones administrativas, es muy reducido. Por ello es importante volver a señalar que toda la arquitectura de garantías descansa en última instancia en la vigilancia y controles ciudadanos, esto es, en las denominadas garantías sociales que abordaremos en el último apartado de este trabajo.

Existe un tercer tipo de garantías políticas secundarias que son las que se encargan a órganos de control externos, como pueden ser en México las comisiones de derechos humanos. Estas instituciones, al elaborar sus

37 Un análisis más detallado de las NOMs se encuentra en Gutiérrez Rivas, Rodrigo et al., op. cit., nota 6, pp. 141 y ss. 
investigaciones, rendir informes y emitir recomendaciones, cumplen funciones de control político, pero una vez que han sido violadas las garantías primarias. Aunque en nuestro país la mayoría de ellas continúan focalizadas en los derechos civiles y políticos, algunas han comenzado a abordar problemas de derechos sociales (especialmente relativos a la salud). Aun cuando en este trabajo nos hemos ocupado principalmente de las garantías que existen a escala federal, conviene aquí referirse a la recomendación 9/2003 ${ }^{38}$ que emitió la Comisión de Derechos Humanos del Distrito Federal exigiendo a las autoridades administrativas de esta entidad resolver el problema de una inmensa fuga de agua. Lo anterior en defensa del derecho fundamental al agua, del colectivo de usuarios de agua potable del Distrito Federal, cuyo fundamento legal fue la OG 15 del Comité DESC. Por su parte, la Comisión Nacional de Derechos Humanos también ha abordado problemas relativos al agua pero sin aprovechar el avance habido en el derecho internacional de los derechos humanos en la materia. ${ }^{39}$

\section{Garantías jurisdiccionales}

Las garantías jurisdiccionales son garantías institucionales depositadas en tribunales (terceros independientes), quienes a petición de personas o grupos agraviados analizan la posible violación de garantías primarias y en caso de encontrarlas, están facultados para sancionar a quienes hubieran violado el derecho y obligar a cumplir las obligaciones que se desprendan del mismo e incluso a reparar el daño.

Estas garantías pueden estar encomendadas a tribunales ordinarios (penales, civiles, administrativos) cuya función es vigilar el cumplimiento de la ley a cargo de órganos administrativos o de particulares. Si bien éstos no suelen abordar los conflictos que se les plantean desde una perspectiva de los derechos, estas instancias en muchos casos deben resolver temas relacionado con alguno de los elementos del contenido de los derechos y están obligados por el sistema jurídico a tomar en cuenta dichas normas. En México, las cuestiones relativas al agua suelen plantearse

38 Recomendación 9/2003, expediente CDHDF/122/03/CUAUH/D0079.002. Investigación de Oficio.

39 Recomendación 047/2002. Sobre el caso de los usuarios del distrito de riego 025, del 13 de diciembre de 2002. 
ante los tribunales administrativos para denunciar la violación de la legislación (LAN, LGEEPA, NOMs) por parte de las autoridades responsables; ${ }^{40}$ sin embargo, también se podría acudir a tribunales civiles para resolver un conflicto entre particulares en la materia; incluso, se puede presentar la denuncia de un delito relacionado con el tema ante la Procuraduría General de Justicia. ${ }^{41}$

No obstante lo anterior, a quienes suelen encomendarse las garantías secundarias de los derechos es a tribunales especiales que normalmente gozan de mayor jerarquía dentro de los sistemas jurídicos. En México, son los tribunales federales (juzgados de distrito, tribunales colegiados y Suprema Corte) quienes, en el marco de un complejo sistema de competencias y atribuciones, están facultados para conocer y resolver los planteamientos sobre violación de derechos.

Sin embargo, los problemas del agua tampoco han sido abordados por dichos tribunales desde la perspectiva de los derechos fundamentales por tres razones principalmente: 1) en primer lugar por la lenta apertura de nuestros tribunales federales en la incorporación de normas y pactos internacionales (que sí reconocen el derecho), así como el desconocimiento que la mayoría de jueces, magistrados y ministros tienen de las interpretaciones autorizadas de los estándares internacionales generadas por diversos órganos de la ONU y la OEA; 2) en segundo lugar, porque

40 En materia de agua la autoridad más importante es la Comisión Nacional del Agua (CNA) que es un órgano desconcentrado de la Secretaría de Medio Ambiente y Recursos Naturales; sin embargo, existen muchas otras autoridades administrativas que también tienen facultades en la materia y por tanto podrían ser autoridades responsables en un litigio administrativo.

41 El Código Penal establece en el artículo 395 una pena de tres meses a cinco años de prisión a quien cometa el delito de despojo, es decir, al que de propia autoridad y con violencia o furtivamente o empleando amenaza haga uso de un derecho real que no le pertenezca. La fracción III de dicho artículo tipifica el despojo de aguas.

En el artículo 414 se establece una pena de uno a nueve años de prisión a quien ilícitamente, o sin aplicar las medidas de prevención o seguridad... realice actividades con sustancias peligrosas y cause un daño a los recursos naturales o a la calidad del agua.

En el artículo 416 se castiga a quien ilícitamente descargue, deposite o infiltre, lo autorice u ordene, aguas residuales, líquidos químicos o bioquímicos, desechos o contaminantes en los suelos, subsuelos, aguas marinas, ríos, cuencas, vasos o demás depósitos o corrientes de agua de competencia federal, que cause un riesgo de daño o dañe a los recursos naturales, a la flora, a la fauna, a la calidad del agua, a los ecosistemas o al ambiente. 
nuestros mecanismos de protección de derechos están construidos a partir de la teoría decimonónica del derecho subjetivo, cuyos objetivos eran la protección de derechos patrimoniales y la solución de conflictos individuales; 3 ) en tercer lugar, porque en el ámbito jurisdiccional de nuestro país, continúan dominando las tesis que consideran a los derechos sociales como cláusulas programáticas que no vinculan a los poderes. No es éste el espacio para profundizar en los argumentos tradicionales que siguen subsistiendo en el ámbito de la judicatura sobre la no justiciabilidad de los derechos sociales; 42 lo que es un hecho, es que nuestros tribunales federales continúan distinguiendo entre garantías individuales y derechos sociales, desempeñando un papel conservador que no propicia la protección de estos últimos; esta posición da como resultado, en el caso del agua, que millones de personas queden sin protección jurisdiccional en la materia y por tanto frente a la omisión del legislador o de la administración, no pueden reclamar la falta de acceso a una cantidad mínima de este recurso para gozar de la libertad y la autonomía que les permitiría desarrollar sus planes de vida, así como el ejercicio de otros derechos fundamentales con los que este recurso/necesidad está íntimamente relacionado. Al no encontrar vías institucionales de reclamo, los grupos sociales se ven orillados a plantear sus exigencias a través de vías no institucionales que - para cerrar el cuadro de violaciones a los derechosobtienen como respuesta institucional la criminalización, la persecución y el encarcelamiento, contribuyendo así a la tensión y la polarización ciudadanas.

Por lo anterior es muy relevante que desde la doctrina continúe insistiéndose en que todos los derechos reconocidos en una Constitución son derechos fundamentales con aplicación directa, son interdependientes, gozan de igual jerarquía y por tanto deben ser protegidos en sede jurisdiccional como cualquier otro. Asimismo, es relevante que tanto los movimientos sociales como los abogados que los acompañen, continúen presentando demandas en defensa de las necesidades que estos derechos buscan garantizar con el objetivo de aportar argumentos ante la propia

42 Un trabajo sobre los obstáculos para la justiciabilidad de lo derechos sociales en México lo tenemos en Gutiérrez Rivas, Rodrigo, "Jueces y derechos sociales en México: apenas un eco para los más pobres", Reforma Judicial. Revista Mexicana de Justicia, México, núm. 6, julio-diciembre de 2005. 
jurisdicción que permita abrir los cauces para que los derechos sociales en México estén también protegidos por garantías secundarias.

No es el objetivo de este trabajo simplificar el debate sobre los derechos sociales y el agua. Existen aspectos relevantes y complejos que se deben abordar: determinación de la conducta debida, contenidos mínimos, aplicación directa de la Constitución, identificación de los sujetos de los derechos así como construcción de vías adecuadas para la solución, entre otros; sin embargo, lo que es inaplazable que el debate se abra. La apertura del mismo en otros tribunales como los europeos, argentinos, colombianos así como en la doctrina no nos permiten seguir defendiendo las tesis de las líneas programáticas; mucho menos en una sociedad como la mexicana, caracterizada por indignantes niveles de desigualdad y distribución inequitativa de la riqueza.

Resumiendo, debe decirse que las principales garantías secundarias de las que se podría echar mano en la actualidad dentro del sistema jurídico mexicanoson las del juicio de amparo, las controversias constitucionales y las acciones de inconstitucionalidad. Con voluntad política por parte de los operadores jurídicos, estas tres pueden ser vías apropiadas para resolver conflictos relacionados con el agua; ya sea a través de una petición ciudadana que plantee el derecho al agua a través del amparo, de una minoría política (o de la Comisión de Derechos Humanos) que impugne una ley a través de una acción, o bien que algún órgano de la administración municipal o estatal plantee su inconformidad frente a una ley o un acto de otro órgano, exigiendo el acceso o la disponibilidad del agua de las personas a las que gobierna.

\section{Garantías sociales}

Hasta ahora, a través del análisis emprendido en el trabajo, se han identificado algunos de los mecanismos institucionales más destacados dentro del sistema jurídico mexicano que pensamos podrían ser utilizados para garantizar el derecho al agua. Se ha tratado, por tanto, de una aproximación jurídica tradicional al problema de las garantías, basada en la presunción de que las instituciones cumplen con sus responsabilidades y son capaces de establecer una vigilancia recíproca para construir un sistema de autolimitación institucional.

Sin embargo, no conviene pasar por alto la paradoja que está detrás de todo Estado constitucional y su sistema de garantías; y es que, recono- 
ciendo que el poder político difícilmente se autolimita, las garantías de los derechos - que son instrumentos para controlar el poder- están en manos del propio poder. Esta paradoja de todo Estado constitucional supone mayores riesgos en países como México, cuyo sistema de garantías se desarrolló bajo la lógica de un Estado autoritario, donde todos los poderes institucionales se mantuvieron unidos por un partido hegemónico y bajo la dirección de un poder ejecutivo federal omnipresente. Aun cuando el sistema de partido hegemónico hoy se ha roto, sobreviven en el país muchas de las viejas estructuras autoritarias que dificultan la independencia real de los distintos poderes y el posible control recíproco entre ellos.

Es una realidad, y un aprendizaje histórico de personas y grupos, que la autolimitación institucional sigue siendo en muchas partes del país una ficción jurídica y una estrategia de legitimación del ejercicio del poder. Por lo tanto, dejar sólo en manos de las instituciones - bajo el argumento del control recíproco entre autoridades - las garantías de protección de los derechos, y en nuestro caso del derecho al agua, es un riesgo que la ciudadanía no puede correr. Para evitar que las herramientas institucionales de protección de los derechos se conviertan en una ilusión que se desvanece en el primer intento de ejercicio, es necesario que sean impulsadas y reforzadas por la propia ciudadanía organizada. Por tanto, de forma paralela a la actuación estatal en defensa de los derechos, es indispensable organizar la fuerza social suficiente que sea capaz de ejercer la presión popular necesaria para asegurar que las autoridades cumplan con sus responsabilidades y no transgredan el orden jurídico que las faculta, obliga y limita.

Las garantías sociales, son por tanto todos aquellos mecanismos de tutela que no están en manos de las instituciones sino de los propios titulares de los derechos. Es la propia ciudadanía actuando a través de diversas vías para asegurar que los derechos sean dotados de contenido, protegidos sin discriminación, respaldados con el máximo de los recursos disponibles, que no sufran de medidas regresivas, etcétera. Para su mejor comprensión conviene dividir a estas garantías extrainstitucionales entre: a) garantías de participación indirecta, y b) garantías de acción directa.

a) Las garantías de participación indirecta son todas aquellas vías a través de las cuales los ciudadanos pueden participar en la construcción institucional de las garantías del derecho al agua. Una primera que inte- 
resa señalar son las garantías de elección. El hecho de que en las democracias participativas los ciudadanos puedan votar y ser votados, supone la posibilidad de elegir o destituir a las personas que ocupen cargos de elección y que en un momento dado puedan tomar decisiones legislativas o administrativas a favor o en contra del derecho fundamental al agua. Se trata de un mecanismo de control indirecto y en la actualidad bastante débil por la lógica partidista que domina las democracias contemporáneas.

De forma paralela a esta garantía ejercida a través del voto, los grupos y movimientos sociales también pueden organizarse y emprender acciones para exigir información a las autoridades y, con base en ella, realizar un esfuerzo de crítica y control sobre las políticas públicas en materia de agua, leyes e incluso resoluciones judiciales o administrativas. Desgraciadamente en nuestro país no existe la posibilidad de que la propia ciudadanía pueda hacer llegar a las instituciones iniciativas de ley o de reforma constitucional (iniciativa popular), pero sí puede organizarse para ejercer presión sobre los órganos que tienen esta facultad. ${ }^{43}$ En el ámbito presupuestario, si la ciudadanía solicita la información adecuada, y se vincula con expertos en la materia, podría incluso ejercer controles ciudadanos sobre el gasto público, exigiendo a las autoridades una asignación de los recursos públicos dirigida a atender los temas prioritarios establecidos por la Constitución y los tratados internacionales, como lo son todos los derechos en ella incluidos. En el tema del agua se debería exigir que los problemas de acceso, disponibilidad y calidad estuvieran en la agenda prioritaria de la administración para que ésta supervisara la observancia del contenido mínimo del derecho, su materialización progresi-

43 En México las iniciativas de ley y de reforma constitucional están reservadas al titular del Poder Ejecutivo y a cualquier representante del Poder Legislativo. Conviene destacar que el artículo 6o. fracción VIII de la Ley de la Comisión Nacional de los Derechos Humanos, faculta a dicho órgano constitucional autónomo para "Proponer a las diversas autoridades del país... promuevan los cambios y modificaciones de disposiciones legislativas y reglamentarias así como de prácticas administrativas que, a juicio de la Comisión Nacional, redunden en una mejor protección de los derechos humanos". Si bien no se trata de una iniciativa legislativa, la ciudadanía podría presionar a la Comisión para que ésta, en ejercicio de sus facultades, proponga los cambios que la Constitución y la legislación requieren para armonizar el derecho interno con el derecho internacional y se cumpla con la obligación estatal de incorporar el derecho humano al agua en nuestro orden jurídico interno. 
va y sin discriminación, así como la atención a los grupos que se encuentren en situación de mayor urgencia y vulnerabilidad.

b) Junto a estas acciones de participación ciudadana en la construcción de las garantías institucionales, también se suelen poner en marcha estrategias de acción directa para reclamar, e incluso autotutelar, el derecho al agua. Aunque se trata de vías no institucionales, en la mayoría de los casos se encuentran en el marco de la Constitución y las leyes.

Este es el caso, por ejemplo, de la conformación de sistemas comunitarios o indígenas de gestión y distribución del agua, a través de los cuales las propias comunidades toman las decisiones relativas al acceso de las personas al recurso que protege el derecho. Si en un inicio se trató de esfuerzos ciudadanos no previstos por la ley, hoy existe un reconocimiento de los mismos en la legislación local que amplía los márgenes de decisión de las propias comunidades (mecanismos más democráticos) sobre uso y distribución del agua. ${ }^{44}$

También es común que en ejercicio de los derechos de asociación y manifestación se organicen marchas ciudadanas y plantones en plazas públicas para demandar la protección del derecho. Así como la difusión de información a través de boletines, conferencias de prensa, volantes y panfletos elaborados por las propias comunidades.

Ahora bien, en sistemas políticos y jurídicos como el mexicano, donde las garantías institucionales suelen estar bloqueadas para las personas en situación de mayor urgencia y discriminación, y donde existen situaciones extremas de exclusión en el acceso al agua, los pueblos y comunidades se ven obligados a emprender medidas de visibilización y protección más radicales. Por ejemplo, detener la construcción de obras y el paso de maquinaria que amenazan la disponibilidad o la calidad del agua en una región, acciones de desobediencia civil como boicots de consumidores

44 Esta forma de autotutela del derecho al agua ha sido impulsada por múltiples comunidades indígenas y campesinas del estado de Morelos. Éstas han constituido sistemas de agua comunitarios, cuya función es gestionar y distribuir el recurso al interior de sus pueblos. La misma se instrumentó como un mecanismo de defensa de las comunidades frente a una iniciativa de reforma legislativa del gobierno estatal (Lauro Ortega 1982-1988) a través de la cual se intentó trasladar la responsabilidad de la gestión del agua a empresas privadas. A través de la movilización de las comunidades se logró que la ley reconociera la posibilidad de que las propias comunidades gestionaran sus recursos hídricos. 
en contra de los altos costos del agua o incluso de resistencia civil activa como la toma de pozos.

Debido a que muchas de estas estrategias de defensa de derechos suelen afectar los intereses patrimoniales de otros grupos y personas, en muchos casos la reacción estatal suele ser violenta, y por lo general desproporcionada. Normalmente suele haber una utilización política del derecho penal, criminalizando la protesta y la manifestación de las ideas $\mathrm{y}$, en otros casos, intervención policiaca desmesurada a través de la cual se intimida a las comunidades, se les persigue. En muchos casos todo ello deriva en la violación de otros derechos integridad física, debido proceso, libertad personal e incluso el derecho a la vida. ${ }^{45}$

Es importante señalar que desde una perspectiva garantista de los derechos, que ponga en primer lugar la satisfacción de las necesidades e intereses más relevantes de todas las personas, pero especialmente de quienes se encuentran en una situación de mayor discriminación, debería tomarse en cuenta que la mayor parte de los movimientos y luchas sociales por el agua en el país surgen por la situación general de exclusión en la que se encuentran millones de personas debido a que las distintas esferas de gobierno no cumplen con sus obligaciones, impactando con ello de forma grave en la vida diaria de las personas y en el desarrollo de los pueblos.

\section{CONCLUSIÓN}

Como se ha expuesto en el trabajo, los esfuerzos que realizan personas y comunidades por acceder al agua no cejarán en tanto se trata de un re-

45 Así lo ha documentado la Comisión Civil Internacional de Observación por los Derechos Humanos que en las conclusiones de su Informe de 2008 señaló: "como han venido demostrando el número de amparos concedidos, la inmensa mayoría de los actuales procesamientos y condenas se han fundamentado jurídicamente en detenciones arbitrarias en las que se han venido fabricando delitos... posesión de drogas o de armas y en ocasiones también otros delitos como robo, agresión sexual y hasta homicidio... la lógica de estos mecanismo es la de criminalizar a los miembros de movimientos sociales evitando además que puedan ser considerados como presos políticos. 7. En esta lógica represiva se ha venido abusando del recurso a la cárcel. Tanto de la prisión provisional, utilizando más allá de los fines cautelares para la que está pensada, como de la pena de prisión con condena de más de 67 años". CCIODH, Informe de la situación de los derechos humanos en Chiapas, Oaxaca y Atenco, VI visita, 30 de enero-20 de febrero, 2008.

Fecha de recepción:

Fecha de dictamen: 
curso que es indispensable para la vida. Si bien la lucha por la constitucionalización del derecho es una estrategia conveniente, que es necesario seguir impulsando, no puede ser la única en la que se concentren todos los esfuerzos. En la actualidad, el sistema complejo de garantías, previsto por el ordenamiento jurídico mexicano, abre distintas vías para que quienes se encuentran en situación de grave escasez y discriminación luchen por el acceso al líquido. Una buena estrategia para los pueblos y comunidades es articular de forma paralela garantías institucionales y sociales que permitan construir diversos frentes de presión que permitirán abrir más opciones para poder acceder a sus recursos hídricos. 